\title{
Лингвистические штудии
}

\section{DOI: $10.37005 / 2687-0231-2020-0-5-32-38$}

УДК 8-811.111

\section{С. Б. Волкова}

\section{Лексема finger в составе английских фразеологизмов}

\begin{abstract}
Аннотация:
В статье рассматриваются английские идиомы, имеющие в своем составе лексему finger, и предлагается их классификация, позволяющая облегчить их изучение и запоминание. Фразеологизмы с компонентом finger анализируются с учетом сложившихся в английской культуре особенностей восприятия пальцев рук и их функций. Автор показывает, как различные ассоциации, связанные с пальцами, привели к возникновению столь многообразных идиом.
\end{abstract}

Ключевые слова: лексема, соматический компонент, фразеология, лингвокультурология

\section{Об авторе:}

Волкова Светлана Борисовна, кандидат филологических наук, Государственный университет «Дубна», доцент кафедры лингвистики факультета социальных и гуманитарных наук; эл. почта: volkovasvetlana@mail.ru

Интерес к фразеологическим единицам, имеющим в своем составе соматический компонент, т. е. название какой-либо части человеческого тела, не иссякает. По мнению исследователей, «эта лексика широко отражает реалии окружающего мира» [3, с. 22]. Она конкретна и наглядна, а потому легко усваивается как носителями языка, так и теми, кто изучает этот язык как иностранный. Знание и понимание фразеологизмов открывает много возможностей. Фразеология - «зеркало культуры», кладезь народной мудрости, так как в ней находят отражение национально-культурные особенности языка. Уместное употребление фразеологизмов обогащает речь, способствует сохранению культурных концептов в языковой системе. При этом понимание и употребление фразеологизмов 
нередко вызывает трудности. Фразеологические единицы встречаются и на страницах художественных произведений, и в публицистических текстах, где эти устойчивые сочетания могут трансформироваться. Чтобы правильно понять их смысл, нужно точно знать их основное значение - помимо дополнительного стилистического значения, которое привносится контекстом.

Цель данного исследования - выделить и проанализировать английские идиомы с общим компонентом “finger”. Одна из задач - упорядочить, классифицировать выделенные идиомы, чтобы найти более эффективный способ их изучения и запоминания, подсказать, как сделать их восприятие более доступным. Вторая задача исследования (условно говоря, лингвокультурологическая) - попытаться выявить на основе выделенных единиц национально-культурные особенности англоязычной лексики.

Исследований в области фразеологии с соматическими компонентами немало. Часто лингвисты задаются целью сопоставить различные виды соматических фразеологизмов в двух и более языках, чтобы выяснить, совпадает или не совпадает их образность, общее значение и структурно-грамматический тип. Широко исследуется и проблема перевода фразеологизмов; в этом аспекте выделяют, во-первых, полные эквиваленты, во-вторых, фразеологизмы, которые частично совпадают в разных языках, и, в-третьих, такие, которые не совпадают совсем (при их переводе необходимо прибегать к объяснению).

Для преподавания иностранных языков важна техника запоминания. Фразеологизм «представляет собой раздельно сформированную лексическую единицу и является семантическим эквивалентом слова» [3, с. 23], поэтому при его запоминании разумно использовать тот же метод, что и при изучении лексики - метод ассоциаций. Чтобы обнаружить связанные с соматическими фразеологизмами ассоциации, следует сначала вспомнить, какова роль или функция той или иной части тела в объективной действительности. Например, с лексемой “hand” (рука) возникают ассоциации «работа, труд», “mouth" (рот) воспринимается как «источник коммуникации», “ears” (уши) «способность слышать и слушать» и, возможно, «любопытство». Какими же характеристиками обладают пальцы на руке?

Прежде чем ответить на этот вопрос, обратимся к истории слова finger. Этимологически эта лексема - исконно английская. Первоначально ее корень употреблялся в значении «пять» (finger-O.E. fingor, from P.Gmc. *fingraz, with descendants widespread in the Gmc. languages but no cognates elsewhere; perhaps connected with PIE *pengke, the root 
meaning "five"). В качестве единицы измерения, а именно в значении «ширина пальца», что составляет $3 / 4$ дюйма (=19 мм), данная лексема начала употребляться в среднеанглийский период (as a unit of measure (M.E.) it represents the breadth of a finger, about three-quarters of an inch). Значение глагола to finger «опознать преступника, донести на кого-либо» впервые датировано 1930 г. В современном языке лексема многозначна. Одно из значений представляет собой метафорический перенос на предмет (объект), который по форме, внешнему виду напоминает палец (finger - 1 your fingers are the long thin parts on the end of your hands; 1 a the part of a piece of clothing that covers one of your fingers; 2 a long thin piece of something: fingers of toast) [5, c. 523].

Перейдем к наименованиям пальцев на руке и к их происхождению. Несмотря на то, что указательный палец идет после большого, именно он считается первым. Это отражено в самом его названии - "fore finger" (fore - «передний», «впереди»). Наименование большого пальца - thumb - происходит от глагола «набухать, опухать» (“tum” = “toswell”). В английском языке принято говорить “four fingers and a thumb", подчеркивая тем самым отличие большого пальца от других. Указательный именуется pointer finger - от глагола to point out («указывать»). Наименование среднего пальца - middle finger- имеет буквальное значение, так как этот палец располагается в центре (middle) руки. Тот палец, который в русском языке называется безымянным, в английском - «перстневой», ring finger. Он получил свое название из-за нерва, который проходит через него и соединяет его с сердцем, поэтому безымянный палец символизирует романтические отношения - на нем носят обручальное кольцо. Кроме того, именно этим пальцем в старину растирали лекарство, чтобы сразу же почувствовать, вредное оно для здоровья или нет. В результате появилось еще одно наименование - medical finger (медицинский палец). Мизинец называется «маленьким пальцем» - little / baby finger. Он может также именоваться pinky / pinkie, от слова «маленький» (“pinky”=”small”).

Каждый из пальцев имеет определенное значение в астрологии и хиромантии. Мизинец ассоциируется с умом и убедительностью, безымянный - с романтическими отношениями; средний палец символизирует баланс и ответственность, указательный власть, лидерство, полномочия; большой палец указывает на характер. Крепкий, прямой палец говорит о властной личности, а кривой считается признаком злобы или нечестности.

Словосочетание finger language, означающее в английском языке язык жестов (язык глухонемых), подчеркивает преобладающую роль пальцев рук в невербальном общении, их 
способность с помощью жестов дополнять или полностью заменять речь. Тело человека а в первую очередь, его руки и, в частности, пальцы - подсознательно и спонтанно передает его эмоции и полученные им впечатления. Определенные жесты зафиксированы во фразеологии. Это так называемые симптоматические жесты, которые свидетельствуют об эмоциональном состоянии человека. Например, выражение cross your fingers / keep your fingers crossed - to hope that things will happen in the way you want them to (стараться не сглазить) - восходит к народной примете: суеверные люди держат пальцы скрещенными, считая, что это отвратит неудачу. В американской культуре этот жест и соответствующее ему словосочетание приобрели еще один смысл: если скрестить пальцы и при этом лгать, то сказанное не считается ложью. Симптоматическим жестам соответствуют и другие фразеологизмы: put / stick two fingers up at smb (BrE, informal)-to express anger at someone in a very rude way by holding up your first two fingers in the shape of a " $V$ " with your palm facing you; give smb the finger (mainly AmE) - to express anger at someone in a very rude way by holding up your longest finger towards them with you palm facing you. Обе эти идиомы имеют отрицательные коннотации, так как обозначенные ими жесты (поднятый вверх средний палец или средний вместе с указательным, в обоих случаях - при повернутой к себе ладони) несут в себе негативную экспрессию и выражают такие не одобряемые обществом эмоции, как злость и раздражение.

Жест «указывать пальцем» воспринимается как повелительный, властный, интерпретируется как демонстрирующий агрессию и злость, как проявление высокомерия и желания унизить. Соответственно, идиомы, связанные с таким жестом, имеют явно отрицательные коннотации. Например: to point the finger of scorn at smb - показывать пальцем на кого-либо, насмехаться над кем-либо, презрительно о ком-либо отзываться; to snap one's fingers at smb - игнорировать кого-либо, что-либо.

В устойчивых словосочетаниях особое внимание уделено трем пальцам: мизинцу, большому и, предположительно, указательному (это предположение основано на том, что в состав идиом входит глагол point):

- $\quad$ not to be worth smb's little finger - не стоить чьего-либо мизинца, быть недостойным кого-либо;

- turn / twist smb round one's little finger - помыкать кем-либо, веревки вить, заставлять плясать под свою дудку; 
- crook (lift, raise, throw, turn up) the little finger (coll.) - напиться, хватитьлишнего (a crooked finger is not straight or healthy)

- $\quad$ one's fingers are all thumbs/be all thumbs - неловкий, неуклюжийчеловек, растяпа;

- $\quad$ the finger of Fate /of God - перст судьбы, перст божий, указующий перст;

- $\quad$ point an accusing finger at - показывать пальцем на кого-либо, обвинять.

Как видно из примеров, большой палец ассоциируется с неуклюжестью, неловкостью; указательный - с перстом судьбы и с обвинением.

На кончиках пальцев располагается наибольшее количество тактильных рецепторов. Пальцы на руках подвижны, чувствительны и реагируют на команды мозга с особой точностью. Тактильные ощущения, то есть ощущения прикосновения, позволяют познавать мир. Поэтому глагол “to finger” отражает не только способность человека воспринимать окружающее на ощупь: он получил значение «выявлять, определять, выделять, замечать что-либо». Способность пальцев к тактильным ощущениям прямо или косвенно реализуется в следующих идиомах: burn one's fingers - обжечься на чем-либо; put one's fingers in the fire - напрашиваться на неприятности, рисковать, лезть на рожон (оба фразеологизма обладают отрицательной коннотацией); to have your finger on the pulse внимательно следить за чем-либо, быть в курсе дела (to be conscious of new developments in a situation); have a finger in the pie - принимать участие в чем-либо, во все вмешиваться, иметь ко всему отношение, быть в каждой бочке затычкой.

Благодаря подвижности, активности, ловкости пальцев лексема finger может служить обозначением инструмента для каких-либо действий. Например, в идиоме lay / put a finger on smb (ударить кого-либо) палец выступает как инструмент физического насилия. Следует отметить, что данная структура употребляется преимущественно в отрицательных предложениях. Пальцы могут быть инструментами для воровства: have light / sticky fingers - брать, что плохо лежит, быть нечистым на руку; stick to smb’s fingers - (1) прилипать к рукам (о деньгах), (2) присвоить, прикарманить.

Пальцы могут и подвести, быть не такими умелыми и ловкими, как нужно. Это отражено, например, в идиоме, характерной для разговорной речи - (have) butter fingers. Ee используют для характеристики человека, у которого все валится из рук; она близка по смыслу к русским выражениям «руки-крюки», «дырявые руки». Фразеологизм (let smb. / 
smth) slip through one'fingers означает «упустить, выпустить из рук; проскользнуть сквозь пальцы, уплывать из рук».

О значении одного из фразеологизмов догадаться трудно: with a wet finger («с мокрым пальцем»). Эта идиома употребляется редко и имеет значение «с легкостью, без труда, запросто». Ее появление объясняется тем, что, листая книгу или любое другое печатное издание, мы смачиваем палец, чтобы облегчить этот процесс.

При изучении идиом была выделена одна национально-культурная особенность речи англичан: из вежливости они стараются избегать прямолинейности, используя слова и структуры, которые можно описать словом tentativeness (предположительность, приблизительность, условность). Этой особенностью объясняется склонность англичан к преуменьшению, к использованию эвфемизмов. При сравнении идиом light fingers и sticky fingers, которые являются стилистическими синонимами, можно заметить, что слово sticky обладает ярко выраженной отрицательной коннотацией (употребляется в значении «липкий, плохой, неприятный, грязный), поэтому в языке возник вариант с его заменой на эвфемизм light.

Обширный корпус фразеологизмов с компонентом finger показывает, что этот соматизм занимает важное место в сознании англичан и отражает многообразие ассоциаций, связанных в английской культуре с пальцами руки и их функциями.

\section{Библиографический список:}

1. Кузьмин С.С. Русско-английский фразеологический словарь переводчика. М.:Флинта: Наука, 2001. 776 с.

2. Кунин А.В. Большой англо-русский фразеологический словарь. 6-е изд., исправл. М.: Живой язык, 2005. 944 с.

3. Орлова Т.Г., Никулина Е.Ф. Учет структурно-семантического сходства и различия английских соматических фразеологических единиц при переводе их на русский язык [Электронный ресурс] // Вестник РУДН. Серия «Теория языка. Семиотика. Семантика». 2011. № 1. С. 22-31. Режим доступа: https://cyberleninka.ru/article/n/uchet-strukturnosemanticheskogo-shodstva-i-razlichiya-angliyskih-somaticheskih-frazeologicheskih-edinits-priperevode-ih-na-russkiy/viewer (Дата обращения: 15.04.2019).

4. Lasane A. How the 5 Fingers Got Their Names [Electronic resource]. URL: https://www.mentalfloss.com/article/74308/how-5-fingers-got-their-names (Access: 10.04.2019). 5. Macmillan English Dictionary for Advanced Learners, International student edition. London: Bloomsbury Publishing Plc, 2006. 1692 p.

6. Merriam-Webster's Learner's dictionary [Electronic resource]. URL: http://www.merriam-webster.com/dictionary (Access: 15.04.2019).

7. Online Etymology Dictionary by Douglas Harper [Electronic resource]. URL: http://www.etymonline.com (Access: 15.04.2019). 
8. Rings \& Finger Symbolism [Electronic resource]. URL: https://www.realmenrealstyle.com/ring-finger-meaning/ (Access: 08.04.2019).

\section{Volkova S.B. Lexeme finger in English phraseological units}

The English idioms with a lexeme "finger" are considered in the present article and their classification is suggested to make the process of their studying and memorizing more effective. The phraseological units with a component "finger"are analyzed taking into account the peculiarities of perception of this body part and its main functions prevailing in English culture. The author demonstrates how various associations connected with fingers have led to the appearance of so many diverse idioms.

Keywords: lexeme, somatic component, phraseology, linguoculturology 